\author{
ARTIGO

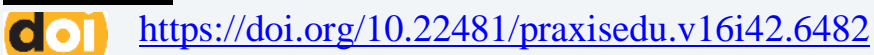

\title{
REFLEXÕES SOBRE A FORMAÇÃO DOCENTE PARA A EDUCAÇÃO BÁSICA NA DISCIPLINA HISTÓRIA MEDIEVAL I
}

\author{
REFLECTIONS ON THE TEACHING TRAINING TO THE BASIC EDUCATION \\ IN THE SIGNATURE MEDIEVAL HISTORY I
}

\begin{abstract}
REFLEXIONES SOBRE LA FORMACIÓN DEL PROFESORADO PARA LA EDUCACIÓN BÁSICA EN LA ASIGNATURA HISTORIA MEDIEVAL I
\end{abstract}

\author{
Luciano José Vianna \\ Universidade de Pernambuco/campus Petrolina - Brasil
}

\begin{abstract}
Resumo: Neste artigo, nosso objetivo é fazer uma reflexão sobre a formação de professores de História para a Educação Básica através da prática docente na disciplina História Medieval I na Universidade de Pernambuco/campus Petrolina. Para isso, analisamos aspectos temáticos com textos de diversos autores e autoras medievalistas; produções voltadas para a formação de professores, através dos estudos de Cruz e Hobold (2018), Fazenda (2012), Gadotti (1995), Lüdke (2012), Macedo (2013), Pimenta (2005), Santos (2012) e Schmidt (2004); e os aspectos didáticos, por meio dos estudos de Bergmann (19891990), Bittencourt (2004), Guimarães (2016), Libâneo (2006), Lück (1995) e Santos, Silva Júnior e Sousa (2016). Inicialmente, apresentamos a proposta da disciplina História Medieval I, especificando principalmente os conteúdos trabalhados na mesma. Em seguida, abordamos a dinâmica da disciplina, apresentando os conceitos trabalhados, a diversidade temática e o exercício de desconstrução das ideias pré-concebidas sobre o período. Posteriormente, voltamos nossa atenção para o viés interdisciplinar aplicado na disciplina e nos atentamos às propostas da BNCC voltadas para o Ensino Fundamental. Como considerações finais, destacamos a principal característica da disciplina com a abordagem de temas contemporâneos de demanda social para auxiliar na formação de professores e na construção da cidadania dos discentes da Educação Básica.
\end{abstract}

Palavras chave: Educação básica. Formação docente. História Medieval.

\begin{abstract}
In this article, our aim is to do a reflection about teaching training of History to the basic education through the teaching practice in the signature of Medieval History I at the Universidade de Pernambuco/campus Petrolina. To do this, we analyse thematical aspects in the text of several medievalists; production to the formation of professors through the studies of Cruz e Hobold (2018), Fazenda (2012), Gadotti (1995), Lüdke (2012), Macedo (2013), Pimenta (2005), Santos (2012) and Schmidt (2004); and didactical aspects through the studies of Bergmann (1989-1990), Bittencourt (2004), Guimarães (2016), Libâneo (2006), Lück (1995) and Santos, Silva Júnior e Sousa (2016). In the first moment, we present the propose of signature of Medieval History I presenting the contains which we work in the same. After that, we problematize the dynamic of the signature, talking about the concepts, the thematical diversity and the exercise of deconstruction of the ideas about the period. So, we turn to the interdisciplinary perspective in the signature, and make attention to the BNCC's proposes
\end{abstract}


to the fundamental teaching. As a final consideration, we highlight the mainly characteristics of the signature with contemporary themes of social demands in order to auxiliary in the teaching training and the construction of the citizenship of the students of Basic Education.

Keywords: Basic Education. Medieval History. Teaching training.

Resumen: En este artículo, nuestro objetivo es hacer una reflexión sobre la formación del profesorado de Historia para la educación básica a través de la práctica docente en la asignatura Historia Medieval I en la Universidade de Pernambuco/campus Petrolina. Para eso, analizamos los aspectos temáticos con los textos de diversos autores y autoras medievalistas; las producciones que comentan aspectos de formación de profesores, a través de los estudios de Cruz e Hobold (2018), Fazenda (2012), Gadotti (1995), Lüdke (2012), Macedo (2013), Pimenta (2005), Santos (2012) y Schmidt (2004); y los aspectos didácticos, por medio de los estudios de Bergmann (1989-1990), Bittencourt (2004), Guimarães (2016), Libâneo (2006), Lück (1995) y Santos, Silva Júnior e Sousa (2016). Inicialmente, presentamos la propuesta de la asignatura Historia Medieval I, especificando sobre todo los contenidos trabajados en la misma. Después, analizamos la dinámica de la asignatura, presentando los conceptos que son trabajados, la diversidad temática y el ejercicio de desconstrucción de las ideas preestablecidas sobre el período. Posteriormente, ponemos nuestra atención para la cuestión interdisciplinar aplicada en la asignatura y las propuestas de la BNCC para la enseñanza fundamental. Como consideraciones finales, resaltamos la principal característica de la asignatura con los temas contemporáneos de demanda social para auxiliar en la formación del profesorado y en la construcción de la ciudadanía de los alumnos de la educación básica.

Palabras clave: Educación básica. Formación del profesorado. Historia Medieval.

\section{Introdução}

Nas últimas décadas, observamos um desenvolvimento dos estudos sobre o Medievo em termos de pesquisas em diversas universidades brasileiras. Comparando o quadro atual com as décadas finais do século passado, ocorreu um avanço e um aumento no número de grupos de estudo e pesquisa, eventos e revistas especializadas voltadas para o estudo deste período. Em termos de medievalistas, observamos também a presença dos mesmos nas universidades em todas as regiões do país, favorecendo, portanto, o desenvolvimento do ensino de História do Medievo nos cursos de formação de professores (AMARAL; LISBÔA, 2019). De forma geral, este aumento ocorrido recentemente, comparado com as décadas finais do século passado, influenciaram não somente o desenvolvimento da pesquisa sobre este período no território brasileiro, mas também favoreceram as reflexões sobre o ensino de História sobre o período medieval nas universidades brasileiras.

De acordo com as reflexões de Bittencourt, os objetivos do processo de ensino de História são cinco: construir uma identidade nacional; constituir identidades; formar cidadãos 
críticos e políticos; formar cidadãos críticos política e intelectualmente; e proporcionar uma formação humanística aos alunos (BITTENCOURT, 2004, p. 99-132). Junto a esta ideia, destacamos o pensamento de Schmidt de que na formação de professores, a sala de aula "não é apenas um espaço onde se transmite informações, mas onde [ocorre] uma relação de interlocutores [que] constroem sentidos" na qual o ensino de História é "dar condições para que o aluno possa participar do processo do fazer, do construir a História" (SCHMIDT, 2004, p. 54-66). Recuperando o artigo 205 da Constituição da República Federativa do Brasil:

A educação, direito de todos e dever do estado e da família, será promovida e incentivada com a colaboração da sociedade, visando ao pleno desenvolvimento da pessoa, seu preparo para o exercício da cidadania e sua qualificação para o trabalho. (BRASIL, 1988).

Neste sentido, as ideias de Bittencourt e Schmidt desembocam no pensamento do medievalista Hilário Franco Júnior, o qual refletiu sobre a importância de se estudar História Medieval no território brasileiro, tema específico deste artigo:

Estudar História - de qualquer época e de qualquer local - não deve ser tarefa utilitarista, não deve "servir" para alguma coisa específica. A função de seu estudo é mais ampla e importante; é desenvolver o espírito crítico, é exercitar a cidadania. Ninguém pode atingir plenamente a maturidade sem conhecer a própria história, e isso inclui, como não poderia deixar de ser, as fases mais recuadas do nosso passado. Assim, estudar História Medieval é tão legítimo quanto optar por qualquer outro período. (FRANCO JÚNIOR, 2011).

A prática da cidadania pelos sujeitos históricos, e aí se incluem as professoras e professores de História, assim como as futuras professoras e professores de História, implica em uma atuação social, em saber (e conhecer) os direitos e deveres e suas práticas e, acima de tudo, em estar atento aos acontecimentos contemporâneos. Neste sentido, o estudante de História, que está em um processo de formação de profissional no contexto universitário, estará inserido, posteriormente, em um processo de formação de cidadãos no contexto escolar. Neste sentido, o ensino de História é considerado como "um valioso contributo para o aprendizado e o exercício da cidadania” (GUIMARÃES, 2016, p. 12). Neste sentido:

A reflexão sobre a construção da cidadania nos espaços escolares implica pensar a formação de professores de história como sujeitos de direitos e deveres, profissionais, cidadãos com postura ética e compromisso social e político com a educação. (GUIMARÃES, 2016, p. 80). 
Como afirmou Marc Bloch em um livro imprescindível para todo estudante de história, intitulado Apologia da História, aquele que não observa o seu mundo ao redor, "nem os homens, nem as coisas, nem os acontecimentos" age "sensatamente renunciando ao título de historiador" (BLOCH, 2001, p. 66). Um currículo de um curso de história, portanto, mesmo quando aborda temporalidades distantes como o Medievo, deve estar voltado para a abordagem crítica de perspectivas contemporâneas que formem um professor de História e que fortaleçam o aspecto da cidadania nos discentes da Educação Básica.

Neste artigo, propomos realizar uma reflexão sobre a nossa práxis pedagógica, apresentando os conteúdos da disciplina História Medieval I que ministramos no contexto universitário. Consideramos que o processo didático deve se preocupar com a formação, o conteúdo e os efeitos da consciência histórica no contexto no qual o ensino é realizado, favorecendo, assim, a formação cidadã:

Uma reflexão é histórico-didática na medida em que investiga seu objeto sob o ponto de vista da prática da vida real, isto é, na medida em que, no que se refere ao ensino e à aprendizagem, se preocupa com o conteúdo que é realmente transmitido, com o que podia e com o que devia ser transmitido. Refletir sobre a História a partir da preocupação da Didática da História significa investigar o que é apreendido no ensino de História (é a tarefa empírica da Didática da História), o que pode ser apreendido (é a tarefa reflexiva da Didática da História) e o que deveria ser apreendido (é a tarefa normativa da Didática da História) (...). Nesse sentido, a didática da História se preocupa com a formação, o conteúdo e os efeitos da consciência histórica num dado contexto sócio histórico. (BERGMANN, 1989-1990, p. 29-42).

Uma proposta com base nesta perspectiva, ou seja, em uma formação de cidadãos política e intelectualmente críticos a partir de uma perspectiva de reflexão histórico-didática, deve problematizar o objeto/conteúdo almejando alcançar a formação da consciência histórica aplicada a um curso de formação de professores. Ou seja, deve haver uma junção de conteúdos entre o que é ensinado em um curso de formação de professores e o que será abordado em um processo de ensino de História na Educação Básica, com destaque para temas atuais e de demanda social. Neste sentido, as demandas curriculares devem coincidir com as demandas sociais.

Sobre este aspecto, é necessário destacar a intrínseca relação constante entre ensino e pesquisa para o desenvolvimento do ensino de História, o que promove, desta forma, na perspectiva de Bergmann, uma reflexão histórico-didática, levando em consideração que a práxis educativa deve preocupar-se com os efeitos da consciência histórica no contexto no qual o ensino é efetivado (BERGMANN, 1989/1990, p. 29-42). Uma proposta com base na 
formação de cidadãos política e intelectualmente críticos a partir de uma perspectiva de reflexão histórico-didática que problematize o objeto/conteúdo abordado, almejando alcançar a formação da consciência histórica, minimiza a possibilidade do futuro professor encontrar uma discrepância entre as práticas que ele aprende na universidade e o que ele ensinará na Educação Básica. Neste sentido, o conteúdo aprendido pelo futuro professor de História não seria estritamente reproduzido em sua atuação na sala de aula: antes haveria um processo no qual este professor-pesquisador elaboraria uma proposta de ensino a partir de sua aprendizagem e não tomando como base única e exclusiva o livro didático.

As reflexões apresentadas neste artigo estão feitas com base na nossa experiência em sala de aula durante os semestres 2018/1, 2018/2, 2019/1 e 2019/2, lecionando a disciplina de História Medieval I no contexto universitário em um curso de formação de professores. Embora as reflexões aqui apresentadas se refiram ao contexto dos anos 2018 e 2019, os anos anteriores, 2016 e 2017, serviram de base para que pudéssemos melhorar as propostas do programa da disciplina. Neste sentido, destacamos que constantemente fomos (e somos) levados à reformulação da nossa práxis pedagógica em sala de aula, uma vez que "o saber docente é plural e amalgamado, abarcando saberes da formação profissional, saberes disciplinares, saberes curriculares e saberes experienciais”, como bem destacaram Cruz e Hobold (2018, p. 238), ocasionando, portanto, "uma releitura dessa prática", o que "contribui para a modificação da ação pedagógica" (SANTOS, 2012, p. 22). Refletindo sobre alguns pontos fundamentais para a formação do professor, como, por exemplo, a análise da estrutura curricular na formação docente, Lucíola Santos afirma que a proposta de formação do profissional reflexivo ganha cada vez mais terreno, uma vez que "a atividade profissional alia-se à atividade de pesquisa e o professor passa a ser visto como um pesquisador-na-ação" (SANTOS, 2012, p. 27). Assim, a postura que tomamos neste artigo é a de um professor reflexivo, ou seja, que atua refletindo sobre a sua prática docente buscando melhorar o ensino e, consequentemente, a formação de professores (PIMENTA, 2005, p. 09-22), visando proporcionar ao futuro docente uma consciência em termos de formação cidadã na Educação Básica.

\section{A proposta da disciplina História Medieval I}

Em um contexto no qual cada vez mais estão em evidência as pesquisas sobre o saber docente, o ensino torna-se uma ação que deve ser constantemente renovada, onde o exercício do ofício: 
[...] se apoia em saberes adquiridos pela experiência acumulada na prática social e coletiva dos professores. A atividade de ensinar estaria, assim, baseada em esquemas práticos, utilizados na condução da atividade docente. Essa é a posição de Sacristan, para quem o saber fazer profissional está relacionado com a condução da prática escolar ou dos conteúdos curriculares e se desenvolve por meio dos esquemas práticos do professor, que constituem modelos de atividades ou de tarefas ligadas a um determinado conteúdo. (SANTOS, 2012, p. 21).

Em termos de medievalismo brasileiro, recentemente foram realizadas algumas reflexões sobre o mesmo, principalmente no que diz respeito à relação entre o desenvolvimento historiográfico sobre os estudos medievais e o ensino de História Medieval no país (AMARAL; LISBÔA, 2019). Por exemplo, questões como aspectos temáticos, a relação com o passado medieval português e debates sobre a continuidade do Medievo no contexto territorial brasileiro estão presentes em produções acadêmicas recentes sobre o período, não somente em termos de pesquisa, mas também em termos de ensino de História. O que se percebe, neste sentido, é que nos últimos aproximadamente vinte anos, o medievalismo brasileiro apresentou diversos desafios, além do fato de manter um diálogo cada vez maior com os aspectos interdisciplinares, favorecendo, assim, um contato entre diversas áreas (História, Filologia, Filosofia, História da Arte e Literatura), exaltando o contexto interdisciplinar, além de deixar de ser cada vez mais um período compreendido como distante da nossa contemporaneidade. Outras reflexões são mais profundas e voltadas para aspectos históricos, demonstrando as raízes medievais do Brasil através da análise de uma interação de aspectos culturais (FRANCO JÚNIOR, 2008, p. 80104).

Um aspecto importante que trabalhamos em nossas práticas em sala de aula é a tentativa de estabelecer um vínculo entre o conteúdo e os temas trabalhados nas disciplinas e o contexto contemporâneo do aluno, uma vez que, para Libâneo, no ensino, “o importante não é a transmissão de conteúdos específicos, mas despertar uma nova forma da relação com a experiência vivida". (2006, p. 33). Neste sentido, mesmo que alguns aspectos conteudistas da disciplina são bem específicos do período e voltados somente para o contexto medieval, sempre que possível fazemos uma relação com o contexto contemporâneo, através das mais variadas possibilidades, para estabelecer uma relação com a contemporaneidade através de aspectos históricos e interdisciplinares para a formação da cidadania, uma vez que "o aluno perde o interesse diante de disciplinas que nada tem a ver com a sua vida, com suas preocupações. Decora muitas vezes aquilo que precisa saber (de forma forçada) para prestar exames e concursos. Passadas as provas, tudo cai no esquecimento" (GADOTTI, 1995, p. 87). No momento da preparação e reflexão sobre o programa a ser ministrado, portanto, o professor 
formador de professores deve estar atento a sua prática pedagógica observando os temas que serão apresentados e problematizados em sala de aula e que servirão como base de formação intelectual do futuro professor de História, de forma que este seja um formador de cidadãos no contexto escolar do ensino básico. Portanto:

[...] para ensinar é necessário que o professor, em sua formação, no exercício de seu ofício e no decorrer de seu processo de desenvolvimento profissional se ocupe e se preocupe com os fundamentos de sua prática. Que ele saiba responder a razão pela qual ensina da forma que ensina. (CRUZ; HOBOLD, 2018, p. 238-239).

A disciplina História Medieval I é ministrada no terceiro período, em um momento no qual os alunos já estão há um ano no curso. A carga horária é de 60 horas e sua característica é obrigatória. Os conteúdos temáticos estão localizados temporalmente entre os séculos III e XI e estão divididos em duas partes. A primeira parte, mais voltada para a constituição do cenário e do território onde os assuntos da disciplina incidem, apresenta os seguintes pontos: 1) Introdução sobre o Medievo: Historiografia, ensino de História Medieval e abordagem metodológica; 2) O final do Império Romano (séculos III-V); 3) A formação dos reinos germânicos (o caso dos Suevos e dos Visigodos); 4) Carlos Magno e a formação dos reinos no Ocidente medieval; 5) O Império Bizantino e 6) O nascimento e a expansão do Islã. As aulas nesta parte são expositivas com a participação dos alunos para a discussão dos temas. Ademais, apresentamos um documentário sobre o Islã, intitulado "Ciência e o Islã: o Império da Razão", de forma a sensibilizar os alunos em formação para os temas que muitas vezes não estão muito presentes nos livros didáticos de História (COSTA, 2016, p. 96-100).

Os temas que abordamos em nossa primeira parte do programa voltam-se, portanto, para a criação de uma identidade contextual específica, a qual, por questões de tempo da disciplina (60 horas), obriga-nos a abordar somente a constituição territorial em torno do Mediterrâneo, a Europa ocidental, o Império Romano Oriental (Império Bizantino), o Oriente médio, o norte da África e a Península Ibérica, a qual tem sido nosso foco de atenção com o caso dos Suevos e dos Visigodos, principalmente a partir das propostas metodológicas apresentadas por José Rivair Macedo (MACEDO, 2013, p. 114-117). Embora não abordemos de forma direta a perspectiva insular britânica, o mundo nórdico, os territórios africanos ao sul do Saara e a própria região asiática, com foco nos séculos X e XI no Japão, tais territorialidades sempre são referendadas nas aulas com a citação e indicação de textos complementares para o estudo.

\footnotetext{
${ }^{1}$ Disponível em: https://www.youtube.com/view_play_list?p=E363BD72E220F9CC. Acesso em: 05 abr. 2020.
} 
Devemos ressaltar também que, mesmo não sendo aprofundados em sala de aula, alguns destes últimos temas comentados são objeto de estudos de alunos orientados por nós, tanto no contexto de monografias de final de curso quanto no contexto de Iniciação Científica. ${ }^{2}$

A segunda parte da disciplina, que pode ser entendida como temática, contempla os seminários temáticos, os temas dos quais são: 1) As mulheres no Medievo: do século $\mathrm{V}$ ao século X; 2) A vida privada como nova ordem; 3) Os aspectos sociais; 4) Os aspectos econômicos; 5) Características da educação medieval; 6) As novas estruturas mentais; 7) O diabo no Alto medievo e 8) A igreja nos primeiros séculos do Medievo. Além destes temas, também nesta segunda parte apresentamos duas aulas expositivas voltadas para os temas "Arte e Arquitetura: o Românico" e "Arqueologia da Religião", além de uma abordagem em termos de ensino de História sobre as possibilidades de uso em sala de aula do filme intitulado "Santo Agostinho". 3

Neste sentido, se a primeira parte da disciplina está voltada para apresentar o espaço geográfico (Mediterrâneo, Ocidente europeu, Império Bizantino, Oriente médio, norte da África e Península Ibérica) entre os séculos III e XI, a segunda parte está destinada a trabalhar os temas presentes neste espaço e tempo, apresentando, portanto, uma proposta multitemática e multidisciplinar, e tendo como norte a relação entre as ideias apresentadas e discutidas nos textos, incluindo os da primeira parte da disciplina.

É necessário tecer alguns comentários sobre alguns pontos que apresentamos acima. Em primeiro lugar, a proposta que desenvolvemos está voltada para a fuga de uma abordagem tradicional no ensino de História Medieval em relação aos primeiros séculos do Medievo, como, por exemplo, a questão temporal (iniciando a discussão entre os séculos III e V e desconsiderando a perspectiva de que o Medievo se inicia no século V); a questão introdutória abordando aspectos historiográficos, de ensino de História e de abordagem metodológica, todos voltados para reflexões contemporâneas e necessárias em relação ao período, e a formação dos Reinos Germânicos, enfatizando o território peninsular ibérico com os casos dos Suevos e dos Visigodos, descolonizando, portanto, nas palavras de José Rivair Macedo, o ensino de História (MACEDO, 2013, p. 114-117). Sobre a segunda parte, destacamos os seminários temáticos sobre os aspectos sociais, no qual observamos a importância do conceito de família para o Medievo, a igreja nos primeiros séculos do Medievo, apresentando principalmente o foco da

\footnotetext{
${ }^{2}$ Os temas e as fontes trabalhadas nestas monografias são: sobre o mundo nórdico (análise da série Vikings), o contexto africano (análise da fonte Crónica del país de los negros, composta no século XVII, mas que se refere aos séculos XI ao XVI).

${ }^{3}$ Disponível em: https://www.youtube.com/watch?v=J_GnesyhWTw. Acesso em: 05 abr. 2020.
} 
constituição social da mesma, fazendo-se presente em ritos sociais, tais como o casamento, a relação com o mundo dos mortos e a reorganização da educação; os aspectos arquitetônicos, através dos quais compreendemos a relação com o contexto social e a utilização do cinema para destacar as potencialidades do mesmo no ensino de História.

Em segundo lugar, ressaltamos a importância da introdução e abordagem de temas contemporâneos no programa da disciplina, como, por exemplo, a História das Mulheres, considerando que há uma relação muito próxima entre as demandas sociais, as reflexões historiográficas, os produtos culturais e o ensino de História. E um dos exemplos clássicos que servem para delinear a relação entre estes âmbitos é justamente o campo histórico que conhecemos atualmente como História das Mulheres, surgido no século passado: a partir de uma demanda social (feminismo nos anos 60 e 70 do século XX), surgiram uma série de reflexões sobre o campo histórico feminino em diversas temporalidades (expansão dos estudos sobre a mulher no mundo universitário), que levou à elaboração de produtos culturais (filmes, literatura, etc...) e cujo reflexo observamos em termos de formação cidadã (como, por exemplo, a Base Nacional Comum Curricular - BNCC - com a temática sobre a História das Mulheres).

Neste sentido:

Como sujeitos atuantes em um curso superior de história, acreditamos que o ensino de História é um campo de investigação que mantém uma relação, ao mesmo tempo, íntima e estranha com a produção do conhecimento da historiografia profissional. A produção particular de saberes históricos dentro da escola possui vínculos com a historiografia profissional, mas também se caracteriza por estar fora dela, e possui uma lógica distinta, suscetível de se converter em objeto de investigação. Nesse sentido, localiza-se em um espaço fronteiriço entre história e educação. Em relação à explicitação das semelhanças, verificamos que as pesquisas, tanto na investigação histórica quanto no ensino, se referem a um conjunto de técnicas de análises; consideram as condições políticas, socioeconômicas e culturais em que se desenvolve a investigação histórica profissional. (SILVA JÚNIOR; SOUSA; SANTOS, 2016, p. 254).

Devemos frisar neste tema do programa, também porque, atualmente, nas orientações que fazemos no curso (iniciação científica, monografias em andamento e monografias defendidas), a proporção de orientações voltadas para este tema se desatacam: das treze monografias defendidas sob nossa orientação entre o segundo semestre de 2018 e o segundo semestre de 2019, seis foram voltadas para o estudo sobre as mulheres no Medievo (natureza/tipologia das fontes trabalhadas: fontes primárias textuais de época; fontes literárias contemporâneas sobre o Medievo; cinema); das catorze monografias que atualmente estão em preparação sob a nossa orientação seis abordam esta temática (natureza/tipologia das fontes 
trabalhadas: fontes primárias textuais de época; fontes primárias visuais de época); e das nove orientações de iniciação científica que realizamos até agora, entre 2016 e hoje, seis trabalharam com este tema, sendo que duas delas em curso atualmente (natureza/tipologia das fontes trabalhadas: fontes primárias textuais de época).

Em terceiro lugar, devemos destacar os caminhos pelos quais realizamos nossa práxis na disciplina História Medieval I, utilizando e problematizando com os alunos, constantemente, fontes escritas do período, imagens de época em sua mais variada composição e suporte, a referência a fontes arquitetônicas e arqueológicas, assim como produções contemporâneas sobre o período, tais como filmes, documentários, games e romances históricos. Estes quatro últimos destacam-se, pois, na maioria das vezes, é através deles que os alunos, antes de entrarem em contato com a disciplina, tem contato com o Medievo, ou, melhor dizendo, com uma representação contemporânea sobre o período (RUIZ-DOMÈNEC, 2011, p. 249-256; 275-290; JIMÉNEZ ALCÁZAR, 2016, p. 75-118).

Neste sentido:

Para se pensar o ensino de História, é fundamental considerar a utilização de diferentes fontes e tipos de documento (escritos, iconográficos, materiais, imateriais) capazes de facilitar a compreensão da relação tempo e espaço e das relações sociais que os geraram. Os registros e vestígios das mais diversas naturezas (mobiliário, instrumentos de trabalho, música etc.) deixados pelos indivíduos carregam em si mesmos a experiência humana, as formas específicas de produção, consumo e circulação, tanto de objetos quanto de saberes. Nessa dimensão, o objeto histórico transforma-se em exercício, em laboratório da memória voltado para a produção de um saber próprio da história. (BNCC, 2018, p. 398).

Considerando as questões anteriores, apresentamos a seguir alguns aspectos que temos trabalhado em sala de aula em nossa práxis educativa no ensino da disciplina História Medieval I, e refletimos sobre os mesmos abordando o conteúdo de História Medieval na BNCC, os conceitos e conteúdos da disciplina, a diversidade temática e a desconstrução de ideias préconcebidas sobre o período e a abordagem interdisciplinar.

\section{O conteúdo de História Medieval na BNCC}

Qual é o conteúdo sobre História Medieval presente na BNCC voltado para o Ensino Fundamental? Devido à abordagem voltada para os aspectos temporais da disciplina História Medieval I, centrar-nos-emos somente nos aspectos referentes à temporalidade entre os séculos III e XI. O conteúdo sobre História Medieval na BNCC localiza-se precisamente no sexto ano, 
o qual está localizado nos "anos finais", e está contemplado por três abordagens: 1) identificação de eventos organizados de forma cronológica e situados no espaço geográfico; 2) o trabalho com diferentes tipos de documentos, com foco na produção circulação e utilização dos mesmos; e 3) considerações sobre as diferentes versões para um mesmo fenômeno histórico de forma a se elaborar opiniões próprias (BNCC, 2018, p. 416).

Observando o conteúdo do documento e concentrando-nos nos objetos do conhecimento, encontramos as seguintes informações. Objetos de conhecimento: 1) A passagem do mundo antigo para o mundo medieval; 2) A fragmentação do poder político na Idade Média; 3) O Mediterrâneo como espaço de interação entre as sociedades da Europa, da África e do Oriente Médio; 4) Senhores e servos no mundo antigo e medieval; 5) Escravidão e trabalho livre em diferentes temporalidades e espaços: Roma Antiga, Europa Medieval, África; 6) O papel da religião cristã, dos mosteiros e da cultura na Idade Média; 7) O papel da mulher na Grécia em Roma, e no período medieval. Com exceção dos itens 4 e 5, os quais trabalhamos a formação do futuro docente na disciplina História Medieval II, os demais itens estão voltados para a disciplina História Medieval I. Assim, estes dois últimos itens serão futuramente temas de outras reflexões em relação à formação de professores.

Uma primeira observação necessária diz respeito a natureza dos temas apresentados acima e as possibilidades de trabalho em sala de aula na formação de professores: fronteiras temporais, política, território, relações sociais, religião, cultura e gênero, os quais, embora importantes para se compreender o período, não são suficientes para a compreensão adequada do período. Sobre os temas destacados, podemos fazer as seguintes observações. Item 1) A passagem do mundo antigo para o medieval pode ser abordada a partir de uma visão flexível e de transformação social e política entre os séculos III e V, fugindo, portanto, de uma proposta de abordagem temporal estática, voltada inclusive para a recuperação de datas. Neste sentido, o aluno passa a ter um entendimento dinâmico do surgimento deste período, ampliando, portanto, as possibilidades de compreensão sobre o mesmo (BARROS, 2009, p. 547-573). Item 2) A fragmentação do poder político na Idade Média pode ser abordada no sentido de uma nova organização política, desmistificando, assim, a ideia de desorganização política que muitas vezes foi associada a este período (SILVA, 2008). Item 3) Uma abordagem voltada para o espaço do Mediterrâneo poderia favorecer no ensino de História a compreensão por parte do aluno de que esta sociedade teve como principal característica a sua dinamicidade e o estabelecimento de contatos, fugindo, portanto, da ideia equivocada da inexistência de locomoção e contatos políticos e culturais entre as diversas regiões ao redor deste território 
(BARROS; DELLA TORRE, 2019), integrando, inclusive, territórios que muitas vezes não são abordados devido a uma perspectiva tradicional sobre o Medievo (voltado apenas para o Ocidente europeu medieval. Item 6) Um dos temas mais importantes e interessantes para se trabalhar o período poderia ser o que está voltado para a abordagem do cristianismo, mosteiros e cultura no Medievo, o qual apresenta uma diversidade de possibilidades a serem destacadas (VAUCHEZ, 1995). Item 7) Por fim, um dos temas mais importantes em termos sociais e que se faz presente na BNCC: o papel da mulher. Não nos alongaremos sobre a importância deste tema tanto em termos de formação docente quanto em termos de conteúdo curricular da Educação Básica, questão que já discutimos páginas atrás. Somente destacamos que, neste caso, poder-se-ia abordar os diferentes espaços de atuação das mulheres no período medieval entre os séculos III e XI, tanto na literatura, na religião, nas relações de poder, na educação, nos aspectos intelectuais, etc..., ou seja, âmbitos que, desde uma perspectiva tradicional de ensino de História Medieval são observados apenas a partir da presença masculina.

Uma segunda observação a se fazer é o fato de o conteúdo destacado na BNCC ser inferior em termos de quantidade em comparação com o que é ensinado no processo de formação de professores. Por outro lado, o fato de que o processo de formação de professores no contexto universitário forneça, apresente e problematize diferentes aspectos do Medievo, com uma bibliografia ampla em termos temáticos, assim como no aspecto de fontes primárias, com uma diversidade em termos de tipologias e suporte, faz com que o futuro docente tenha em mente a amplitude de sua formação ao se deparar com estes temas em livros didáticos. Por exemplo, em diferentes momentos, apresentamos aos alunos uma comparação dos temas debatidos em sala de aula, com os textos utilizados, com as informações que encontramos nos livros didáticos. Outra prática que realizamos na formação de professores é o trabalho em sala de aula com fontes primárias voltadas para o contexto medieval. A utilização de fontes primárias no processo de formação de professores faz com que o aluno compreenda que há outras possibilidades para realizar sua práxis em sala de aula além do livro didático, tais como imagens e textos de época. Tal práxis tem como objetivo não apenas demonstrar para o futuro professor e professora de História a diversidade de fontes e possibilidades de práticas educacionais voltadas para as aulas sobre o Medievo, mas sim que o mesmo deve atuar em termos de pesquisa no momento de preparar suas aulas e voltar-se para o ensino (LÜDKE, 2012, p. 111-120), demonstrando, dessa forma, a indissociabilidade entre pesquisa e ensino no contexto educacional histórico. 
Comparando a proposta de nossa práxis educacional com os cinco itens que vimos acima, observamos que os mesmos apresentam-se um tanto quanto limitados em relação aos que trabalhamos, e, dessa forma, o futuro professor, durante a sua preparação universitária, teria um contato com uma quantidade mais ampla de assuntos do que os destacados na BNCC.

Neste sentido, o conteúdo aprendido pelo futuro professor de História durante o processo de sua formação não seria estritamente repassado em sua atuação nas salas de aula do ensino fundamental e médio: antes haveria um processo no qual este professor-pesquisador, através da pesquisa e de sua aprendizagem pedagógica, elaboraria uma proposta de ensino a partir de sua aprendizagem e não tomando como base única e exclusiva o livro didático. Dessa forma, ao problematizar o conteúdo lecionado propondo uma reflexão histórico-didática para os discentes nossa intenção é proporcionar bases e fundamentos para que o mesmo utilize o livro didático juntamente com outras fontes.

\section{Conceitos e conteúdos abordados, a diversidade temática e a desconstrução de ideias pré- concebidas sobre o período}

Tanto na primeira quanto na segunda parte do programa, durante nossa prática de sala de aula, uma das ações que mais realizamos é a desconstrução de ideias pré-concebidas e equivocadas sobre o Medievo. Os alunos apresentam no início da disciplina História Medieval I, localizada no terceiro período do curso, um conhecimento muitas vezes limitado e equivocado em relação ao período, com o qual tiveram contato, em sua maior parte, durante a Educação Básica (Ensino Fundamental e Médio). Neste sentido, para saber aproximadamente a situação do conhecimento da turma em relação ao conteúdo que será ministrado, a partir de ideias gerais, propomos no primeiro dia de aula a realização de um pequeno exercício de redação, no qual os mesmos devem responder a seguinte pergunta: “O que sei e o que me ensinaram sobre o Medievo?" Desde quando começamos a realizar este exercício, o qual nos fornece, de certa forma, um status questiones sobre o conhecimento de cada aluno em relação ao Medievo, e considerando que os mesmos apresentam uma "experiência acumulada" no momento em que iniciam o curso (SANTOS, 2012, p. 20), conseguimos adaptar, melhorar e, sobretudo, desconstruir diversas ideias em relação ao Medievo que os alunos e alunas apresentam no momento em que iniciam a disciplina.

Tais ideias presentes nas redações que os alunos fazem e entregam no primeiro dia de aula servem como guias para que possamos realizar tais exercícios de desconstrução de acordo 
com o texto/tema que será debatido em cada dia. Um panorama que principalmente temos atuado desde que iniciamos as aulas nesta instituição é o da desconstrução de temas e ideias equivocadas sobre o Medievo, alguns dos quais foram desconstruídos pela historiografia ocidental nas últimas décadas, mas que ainda permanecem presentes e, o pior, chegando aos estudantes. Por exemplo, listamos alguns: 1) o poder exacerbado da igreja neste período; 2) as relações senhoriais vistas exclusivamente como relações de exploração e desconsiderando o contexto da dependência; 3) as ideias equivocadas sobre o mundo feminino no Medievo; 4) a ideia de desorganização política e jurídica no período, principalmente destacando os aspectos dos costumes senhoriais; 5) a própria denominação "Idade Média”, através da qual o período é mais conhecido, em contraposição ao termo "Medievo", deixando de lado uma ideia de que este período se tratava de um momento intermediário entre uma temporalidade (Antiguidade) e outra (Modernidade), entre outros.

Em termos de ensino e pesquisa voltados para a História, é necessário considerar, como afirmamos anteriormente, a coerência (ou incoerência) que muitas vezes encontramos entre a perspectiva historiográfica e o livro didático, e as demandas sociais e o currículo e a formação profissional. Muitas vezes, o professor da Educação Básica se depara com um livro didático que não condiz com uma proposta historiográfica atualizada, ou seja, o que se discute em termos de debates acadêmicos não apresenta um vínculo com o que é ensinado em sala de aula. Um exemplo disso é o fato de ainda encontrarmos muitas vezes em livros didáticos a presença do conceito “invasões bárbaras”, desconstruído por Jacques Le Goff (2016) na década dos anos 60 do século passado. Entretanto, até os dias atuais, ainda nos deparamos com tal conceito presente nos livros didáticos que abordam o conteúdo sobre o Medievo e, consequentemente, o mesmo está presente ainda na formação dos alunos no ensino básico. Temos aqui um exemplo claro do descompasso entre o desenvolvimento historiográfico e o ensino de História, questão que impede, na formação do aluno, não somente uma compreensão melhor sobre o período histórico estudado, mas também, se não houver o desenvolvimento de um pensamento crítico sobre o material estudado, a repetição de aspectos já desconstruídos na perspectiva historiográfica.

Outro conceito que abordamos é o de "família" (PERNOUD, s/d, p. 13-26) no período medieval. Tal conceito é utilizado para destacar não somente os aspectos do Medievo em termos de organização social, abordando, por exemplo, a composição e sucessão dos bens familiares, mas também em termos políticos, destacando a importância da constituição das dinastias. Por exemplo, é um conceito que de certa forma serve também para o conteúdo de História Medieval II, quando destacamos os aspectos da guerra privada, ou seja, da guerra entre famílias que 
ocorreu nos séculos feudais e também a formação da família ampla no feudalismo, incluindo tanto uma perspectiva sanguínea (biológica) quanto política (feudal) (BLOCH, 2001, p. 139176).

Como dissemos acima, a realização dos seminários serve para inserir os temas no espaço e tempo elaborados durante a primeira parte do curso. Neste aspecto, destacamos a diversidade temática da disciplina, favorecendo com que o aluno compreenda o período a partir de uma dinamicidade em termos de temas: âmbito feminino, a vida privada, aspectos sociais, aspectos econômicos, educação medieval, formas de se pensar, o diabo e a igreja nos primeiros séculos medievais, além da abordagem sobre o românico e os aspectos arqueológicos da religião (cristianismo, judaísmo e islamismo). Por exemplo, a figura do diabo é destacada nesta parte da disciplina para os discentes observarem não a figura em si, mas como a igreja se apropriou desse personagem e manteve sua relação com a sociedade. Dessa forma, se estudado em termos temporais durante o Medievo, este personagem pode ser entendido como uma espécie de catalizador de historicidade voltada para as ações da igreja perante a sociedade (BASCHET, 2002, p. 319-331).

\section{A abordagem interdisciplinar}

Segundo Hilton Japiassú, um dos principais nomes referentes à introdução do pensamento interdisciplinar no âmbito intelectual no Brasil nos anos 60/70 do século passado, o advento de uma civilização técnica fez com que ocorresse uma especialização em termos de disciplinas, uma fragmentação do conhecimento e, consequentemente, na formação profissional, um sintoma do que ele denomina como "patologia do saber" (JAPIASSÚ, 1976, p. 10-16). Neste sentido, há a necessidade de, nos cursos de formação de professores, existir uma prática interdisciplinar em suas pesquisas, voltada para explorar as fronteiras entre as disciplinas, assim como aproximar universidade e sociedade, uma vez que aquela depende desta para sobreviver e ter o seu reconhecimento social, como já destacava Japiassú em meados da década de 70 do século passado:

Deveríamos, antes, falar de objeto da interdisciplinaridade. Esta procede, em primeiro lugar, de uma crítica 'universitária' do saber. Trata-se de explorar as fronteiras das disciplinas e as zonas intermediárias entre elas. Em seguida, procede do desejo de uma nova adequação das atividades universitárias às necessidades sócio-profissionais ou econômicas. Portanto, de um lado, a interdisciplinaridade aparece como o instrumento e a expressão de uma crítica interna do saber, como um meio de superar o isolacionismo das disciplinas, 
como uma maneira de abandonar a pseudo-ideologia da independência de cada disciplina relativamente aos outros domínios da atividade humana e aos diversos setores do próprio saber; do outro, como uma modalidade inovadora de adequar as atividades de ensino e de pesquisa às necessidades sócioprofissionais, bem como de superar o fosso que ainda separa a universidade da sociedade. (1976, p. 57).

Neste mesmo sentido, porém, voltado para o aspecto do ensino, temos a reflexão de Heloisa Lück sobre a interdisciplinaridade como forma de integrar as disciplinas curriculares escolares entre si e com a realidade:

Interdisciplinaridade é o processo que envolve a integração e engajamento de educadores, num trabalho conjunto, de interação das disciplinas do currículo escolar entre si e com a realidade, de modo a superar a fragmentação do ensino, objetivando a formação integral dos alunos, a fim de que possam exercer criticamente a cidadania, mediante uma visão global de mundo e serem capazes de enfrentar os problemas complexos, amplos e globais da realidade atual. (1995, p. 64).

$\mathrm{Na}$ atualidade, há uma impossibilidade de se referir ao ensino de História sem observar o desenvolvimento historiográfico. É necessário que estas duas perspectivas andem em constante junção e devem ser observadas pelos professores em formação. No caso do medievalismo brasileiro, o mesmo permaneceu por décadas sem dialogar com outras áreas, tais como História, Filologia, Literatura, Filosofia, História da Arte, etc..., característica que se modificou com a presença no panorama histórico das propostas da História Cultural (FRANCO JÚNIOR; MONGELLI; VIEIRA, 2008, p. 177-219). A partir desta perspectiva, uma vez modificado o cenário observamos uma multiplicação dos objetos de estudo, surgidos muitas das vezes de outras áreas do conhecimento. Devemos relembrar que esta mudança ocorreu a partir de uma perspectiva relacionada à historiografia ocidental: na transição dos anos 70 para 80 do século passado, observa-se uma série de reflexões teórico metodológicas, principalmente advindas da História Cultural, na qual o aspecto interdisciplinar era um dos mais evidentes e necessários (COELHO, 2006, p. 29-33).

$\mathrm{Na}$ interação entre o presente e o passado, observamos uma série de materializações, manifestações e representações sobre o Medievo transmitidas através de releituras e apropriações contextuais, muitas das quais estão presentes em nossa contemporaneidade. Tais ações são compreendidas quando identificamos diversas presenças de aspectos medievais em nosso cotidiano, como, por exemplo, obras literárias contemporâneas que retratam a vida de homens e mulheres do Medievo; um outdoor anunciando a estreia de um filme ambientado no que chamamos de período medieval; ou os comentários de nossos alunos sobre um jogo 
eletrônico ambientado no Medievo. Dessa forma, muitas vezes nos deparamos com manifestações em nosso presente que apresentam um vínculo considerável com o passado, e muitas vezes este passado está voltado para o período medieval. Como afirmou Hilário Franco Júnior (2008, p. 84), “é preciso também um olhar de etnólogo sobre as manifestações vivas do presente que carrega aquela herança", referindo-se aqui à herança medieval na contemporaneidade.

Na disciplina História Medieval I, nossa proposta tem-se pautado por uma visão interdisciplinar na abordagem dos temas em sala de aula. Isso nos auxilia em diversos sentidos, principalmente naquele em demonstrar para o futuro professor em formação os possíveis aspectos que podem ser trabalhados. Para isso, partimos do pressuposto de que, de acordo com Ivani Fazenda (2012, p. 9; p. 11), “a interdisciplinaridade se consolida na ousadia da busca, de uma busca que é sempre pergunta, ou melhor, pesquisa", sendo, portanto, "um processo que precisa ser vivido e exercido." Dessa forma, sempre contextualizamos os aspectos temáticos apresentados com os contextos nos quais se enquadram:

[...] a atitude interdisciplinar não seria apenas resultado de uma simples síntese, mas de sínteses imaginativas audazes; interdisciplinaridade não é categoria de conhecimento, mas de ação; a interdisciplinaridade nos conduz a um exercício de conhecimento: o perguntar e o duvidar; entre as disciplinas e a interdisciplinaridade existe uma diferença de categoria; interdisciplinaridade é a arte do tecido que nunca deixa ocorrer o divórcio entre seus elementos, entretanto, de um tecido bem trançado e flexível; a interdisciplinaridade se desenvolve a partir do desenvolvimento das próprias disciplinas. (FAZENDA, 2012, p. 28-29).

Neste sentido, os aspectos que trabalhamos em nossa práxis e que selecionamos para apresentar neste artigo são quatro: a literatura medieval e a crítica social; as imagens e a pedagogia do visual; o âmbito arquitetônico e as manifestações religiosas; e arqueologia e outras formas materiais de se estudar o período.

Em termos literários, utilizamos em sala de aula fontes primárias que apresentam o gênero literário conhecido como fabliaux, composições muito comuns no Medievo, as quais apresentam uma destacável crítica social em relação a grupos sociais no período. Por exemplo, o conto "A burguesa de Orleãs", presente no livro Fabliaux - cuentos franceses medievales, destaca uma crítica social em relação aos burgueses, cujo personagem que os representa é constantemente enganado por clérigos estudantes (Fabliaux, 2005, p. 75-87). Uma das problematizações que fazemos em relação a este gênero, e em especial a este conto, é que não necessariamente o burguês era realmente enganado; a intenção de denegrir a imagem deste 
grupo era o objetivo. Neste caso, a utilização e problematização deste fabliaux serve para apresentar aos alunos o teor de crítica social que a literatura do período medieval apresenta, neste caso, em termos de grupos sociais.

Outro aspecto que destacamos são as imagens e suas funções pedagógicas. Uma imagem que utilizamos na formação dos alunos para nos referir à imaginária organização social feita pela perspectiva monástica, imagem que pode ser encontrada em livros didáticos em outras versões e que é denominada como "três ordens" é a imagem intitulada Clérigo, cavaleiro e camponês (British Library, MS. Sloane 2435 fol. 85). ${ }^{4}$ Através da mesma, levantamos as seguintes questões, por exemplo: 1) a noção de ordem social no período; 2) a presença/ausência de outros grupos sociais, como os mercadores, comerciantes, burgueses 3) o lugar das mulheres nas representações sociais e o motivo de sua ausência; 4) as relações de poder estabelecidas na imagem; 5) as roupas e os instrumentos que os personagens portam indicam a sua posição social; entre outros.

A arquitetura, em especial o românico, também é outro aspecto que destacamos em nossa práxis docente na disciplina de História Medieval I. Por exemplo, abordamos que o românico foi o primeiro estilo arquitetônico a apresentar características comuns e muito próximas em todo o Ocidente medieval, o que demonstra a preocupação com uma certa uniformidade material da igreja no contexto (GARCIA-VILLOSLADA, 1958, p. 335-347). Também destacamos que a sua organização interna espacial coincidia com a organização social no Medievo, ou seja, entre clérigos e leigos, e os aspectos que esta divisão também apresentava, como, por exemplo, a questão do letramento (os primeiros letrados e os segundos iletrados). (SCHMITT, 2002, p. 237-250). Destacamos também o aspecto do surgimento das relíquias e como estas alteraram a organização espacial dos âmbitos religiosos com o surgimento do deambulatório, por exemplo (ERLANDE-BRANDENBURG, 2002, p. 173-184).

Por fim, os aspectos arqueológicos, principalmente voltados para a religião, também auxiliam na forma de se ver este período de forma distinta. Por exemplo, implicando em um estudo da ocupação de um espaço, de um território, a perspectiva arqueológica auxilia os discentes a compreender o estabelecimento das construções religiosas durante os primeiros séculos do Medievo. Por exemplo, a adaptação/transformação de lugares de culto (contexto do cristianismo x paganismo), os objetos para uso litúrgico, lugares de culto não cristãos, como as sinagogas e as mesquitas, a própria organização espacial interna dos edifícios cristãos, os quais

\footnotetext{
${ }^{4}$ Disponível em: https://web.archive.org/web/20060115103059/http://www.uflib.ufl.edu/hss/medieval/. Acesso em: 04 abr. 2020.
} 
contemplam a presença de um altar - diferentemente da perspectiva judaica e islâmica -, lugares de culto de santos como locais de peregrinação, adaptação de lugares de culto cristão para o culto islâmico e vice versa, entre outros (IZQUIERDO BENITO, 2008, p. 133-157).

As discussões apresentadas até agora nos levam, portanto, a uma abordagem holística, diversa, interdisciplinar e não tradicional dos primeiros séculos do Medievo na disciplina História Medieval I. Os temas trabalhados acima são apresentados no decorrer das aulas, não de forma separada, mas sim entrelaçados aos mais variados contextos históricos abordados na disciplina.

\section{Considerações finais}

Neste artigo, apresentamos algumas reflexões sobre a nossa práxis pedagógica na formação de professores de ensino de História realizada através da disciplina História Medieval I em um contexto universitário, abordando aspectos temáticos, documentais institucionais, didáticos e de formação de professores. Para isso, apresentamos os aspectos historiográficos sobre a disciplina, o seu desenvolvimento no país em termos de ensino e pesquisa, as características do processo de ensino de História e seu vínculo com o exercício da cidadania. Neste caso, como se trata de uma reflexão sobre a formação de futuros professores de História, os mesmos seriam preparados não apenas para ministrar aulas no Ensino Básico, mas também, dentro deste processo, formar futuros cidadãos.

Em um primeiro momento, apresentamos o conteúdo da disciplina História Medieval I, tanto os aspectos de formação do espaço quanto os aspectos temáticos. Destacamos também que as características foram pensadas para fugir ou evitar um ensino de História Medieval tradicional, adaptado ao desenvolvimento historiográfico da área, e seguindo a proposta da descolonização do ensino de História Medieval, aspecto que seguimos através da proposta de José Rivair Macedo. Da mesma forma, ressaltamos a necessidade de trabalhar na disciplina temas contemporâneos e voltados para uma demanda social, como a História das Mulheres. Por fim, a utilização de fontes primárias, das mais distintas tipologias, e as formas contemporâneas de representação do Medievo, também são aspectos importantes que destacamos em nossa práxis pedagógica.

Observamos também o conteúdo de História Medieval presente na BNCC e apontamos algumas possibilidades de trabalho com o mesmo em sala de aula na Educação Básica. Embora a natureza dos temas presentes contemple aspectos do ensino de História Medieval, os mesmos 
não são suficientes para a compreensão adequada do período. Por outro lado, observamos, com isso, que o processo de formação de professores que realizamos na disciplina História Medieval I é amplo em termos temáticos, de discussão de conceitos e de utilização de materiais para a formação docente, o que fornece uma mais ampla formação para o futuro docente, além do aspecto de professor pesquisador, que deve ser estimulado constantemente, justamente porque, muitas vezes, através da análise de materiais, nota-se uma incompatibilidade entre a perspectiva historiográfica e o livro didático, e as demandas sociais e o currículo e a formação profissional.

Destacamos também os conceitos que abordamos em nossa práxis, tais como, a desconstrução do conceito de "invasões bárbaras" e a importância do conceito de "família" no período medieval. A proposta interdisciplinar, que está presente nas reflexões sobre ensino de História atualmente, também foi destacada principalmente nos quatro aspectos que trabalhamos na disciplina: a literatura medieval e a crítica social; as imagens e a pedagogia do visual; o âmbito arquitetônico e as manifestações religiosas; e arqueologia e outras formas materiais de se estudar o período.

Por fim, e este é o aspecto mais importante, é necessário salientar que no processo do ensino deve haver uma preocupação em formar um cidadão consciente dos seus direitos e deveres, atuante na sociedade e interventor na mesma, de forma a fazer com que o mesmo possa estar preparado para atuar em sala de aula no Ensino Básico. A prática e a atuação do profissional, preparado para o ensino de História, ocorrem também em um contexto extramuros universidade, não somente conscientizando as futuras professoras e professores, mas também atuando de forma ativa na sociedade. Neste sentido, um aspecto central para a efetivação desta prática concentra-se na formação de professores, âmbito no qual perpassa a reflexão sobre a perspectiva cidadã.

\section{REFERÊNCIAS}

ALMEIDA, Neri de Barros; DELLA TORRE, Robson. O Mediterrâneo medieval reconsiderado. Unicamp: Editora da Unicamp, 2019.

AMARAL, Clínio; LISBÔA, João. A historiografia medieval no Brasil: de 1990 a 2017. Curitiba: Editora Appris, 2019.

BARROS, José d'Assunção. Passagens de Antiguidade Romana ao Ocidente Medieval: leituras historiográficas de um período limítrofe. História (São Paulo), 28, p. 547-573, 2009. Disponível em: http://www.scielo.br/pdf/his/v28n1/19.pdf. Acesso em: 09 abr. 2020. 
BASCHET, Jérôme. Diabo. In: Dicionário Temático do Ocidente Medieval. V. 1. São Paulo: Edusc, 2002, p. 319-331.

BRASIL. Base Nacional Comum Curricular. Educação é a Base. Brasília:

MEC/CONSED/UNDIME, 2018. Disponível em:

http://basenacionalcomum.mec.gov.br/images/BNCC_EI_EF_110518_versaofinal_site.pdf.

Acesso em: 05 abr. 2020.

BERGMANN, Klaus. A História na Reflexão Didática. Revista Brasileira de História, Vol. 9, Num. 19, p. 29-42, 1989/1990.

BITTENCOURT, Circe Maria Fernandes. Ensino de história: fundamentos e métodos. São Paulo: Cortez, 2004, p. 99-132.

BLOCH, Marc. A sociedade feudal. Lisboa: Edições 70, 2001.

BRASIL. Constituição da República Federativa do Brasil de 1988. Brasília, DF, 1988. Disponível em: http://www.planalto.gov.br/ccivil_03/constituicao/constituicao.htm. Acesso em: 05 abr. 2020.

BRITISH LIBRARY, MS. Sloane 2435, fol. 85.

COELHO, Maria Filomena. Breves reflexões acerca da História Medieval no Brasil. In: SILVA, Andréia Cristina Lopes Frazão da, SILVA, Leila Rodrigues. (Org.). Semana de Estudos Medievais, 6, 2005, Rio de Janeiro. Atas da VI Semana de Estudos Medievais do PEM. Rio de Janeiro: Programa de Estudos Medievais, 2006, p. 29-33.

COSTA, Jéssica Pereira da. O estudo de História do Islã e dos muçulmanos na educação básica: conceitos e representações. Dissertação de Mestrado - Programa de Pós-Graduação em História. Universidade de Caxias do Sul, Caxias do Sul, 2016.

CRUZ, Giseli Barreto da; HOBOLD, Márcia. Prática formativas de professores de cursos de licenciatura: diferentes estratégias para ensinar. In: ANDRÉ, Marli (Org.). Práticas inovadoras na formação de professores. Campinas: Papirus, 2018, p. 237-262.

ERLANDE-BRANDENBURG, Alain. Catedral. In: Dicionário Temático do Ocidente Medieval. V. 1. São Paulo: Edusc, 2002, p. 173-184.

Fabliaux. Cuentos franceses medievales. Madrid: Cátedra, 2005.

FRANCO JÚNIOR, Hilário. Raízes medievais do Brasil. Revista USP, São Paulo, n. 78, p. 80-104, 2008. Disponível em: http://www.revistas.usp.br/revusp/article/view/13680/15498. Acesso em: 09 abr. 2020.

FRANCO JÚNIOR, Hilário; MONGELLI, Lenia Márcia de Medeiros; VIEIRA, Yara Frateschi. Estudos Medievais no Brasil. Revista de poética medieval, Num. 21, p. 177-219, 2008. Disponível em: https://core.ac.uk/download/pdf/58909843.pdf. Acesso em: 09 abr. 2020. 
FAZENDA, Ivani C. Arantes. Interdisciplinaridade: história, teoria e pesquisa. Campinas: Papirus, 2012.

GADOTTI, Moacir. Educação e compromisso. 5. ed. Campinas: Papirus, 1995.

GARCIA-VILLOSLADA, Ricardo. Historia de la Iglesia Católica II. Edad Media (8001303). La cristiandad en el mundo europeu y feudal. Madrid: Biblioteca de Autores Cristianos, 1958, p. 335-347.

GUIMARÃES, Selva. Apresentação. In: GUIMARÃES, Selva (Org.). Ensino de História e cidadania. São Paulo: Papirus editora, 2016, p. 11-21.

IZQUIERDO BENITO, Ricardo. La cultura material en la Edad Media: perspectivas desde la arqueología. Granada: Universidad de Castilla-La Mancha, 2008, p. 133-157.

JAPIASSU, Hilton. Interdisciplinaridade e patologia do saber. Rio de Janeiro: Imago Editora, 1976.

JIMÉNEZ ALCÁZAR, Juan Francisco. De la edad de los imperios a la guerra total: Medievo y Videojuegos. Murcia: Compobell, 2016.

LE GOFF, Jacques. A civilização do ocidente medieval. Rio de Janeiro. Vozes, 2016.

LIBÂNEO, José Carlos. Democratização da escola pública. A pedagogia crítico-social dos conteúdos. São Paulo: Loyola, 2006.

LÜCK, Heloisa. Pedagogia interdisciplinar: fundamentos teórico-metodológicos. Petrópolis: Vozes, 1995.

LÜDKE, Menga. A pesquisa na formação do professor. In: FAZENDA, Ivani C. Arantes. A pesquisa em educação e as transformações do conhecimento. Campinas: Papirus, 2012, p. 111-120.

MACEDO, José Rivair. Repensando a Idade Média no Ensino de História. In: História na sala de aula: conceitos, práticas e propostas. Leandro Karnal (Org.). São Paulo: Contexto, 2013, p. 109-125.

PERNOUD, Régine. Luz sobre a Idade Média. Lisboa: Publicações Europa-América, s/d, p. 13-26.

PIMENTA, Selma Garrido. Professor-pesquisador: mitos e possibilidades. Contrapontos, Vol. 5, Núm. 1, p. 09-22, jan/abr 2005. Disponível:

https://siaiap32.univali.br/seer/index.php/rc/article/view/802/654. Acesso em: 09 abr. 2020.

RUIZ-DOMÈNEC, José Enrique. Entre historias de la Edad Media. Granada: Editorial Universidad de Granada, 2011, p. 249-256; 275-290.

SANTOS, Franciele Amaral Rodrigues dos; SILVA JÚNIOR, Astrogildo Fernandes da Silva; SOUSA, José Josberto Montenegro. Diferentes fontes e linguagens nas aulas de História e a 
formação cidadã de jovens estudantes do Ensino Médio. In: GUIMARÃES, Selva (Org.). Ensino de História e cidadania. Campinas: Papirus Editora, 2016, p. 253-277.

SANTOS, Lucíola Licinio de C. P. Formação do professor e pedagogia crítica. In: FAZENDA, Ivani C. Arantes. A pesquisa em educação e as transformações do conhecimento. Campinas: Papirus, 2012, p. 17-28.

SCHMIDT, Maria Auxiliadora. A formação do professor de História e o cotidiano da sala de aula. In: BITTENCOURT, Circe Maria Fernandes. O saber histórico na sala de aula. São Paulo: Contexto, 2004, p. 54-66.

SCHMITT, Jean-Claude. Clérigos e leigos. In: Dicionário Temático do Ocidente Medieval. V. 1. São Paulo: Edusc, 2002, p. 237-250.

SILVA, Marcelo Cândido da. A realeza cristã na Alta Idade Média. Os fundamentos da autoridade pública no período merovíngio. São Paulo: Alameda, 2008.

VAUCHEZ, André. A Espiritualidade na Idade Média ocidental. Rio de Janeiro: Jorge Zahar, 1995.

\section{SOBRE O AUTOR:}

\section{Luciano José Vianna}

Doutor em Cultures en contacte a la Mediterrània pela Universitat Autònoma de Barcelona (UAB). Pós-Doutor em História pela Universidade Federal de Sergipe (UFS). Professor Adjunto de História Medieval na Universidade de Pernambuco (UPE) campus Petrolina e Professor Permanente do Programa de Pós-Graduação em Formação de Professores e Práticas Interdisciplinares (PPGFPPI) campus Petrolina. Membro do Institut d'Estudis Medievals (UAB-IEM). Coordenador do Spatio Serti - Grupo de Estudos e Pesquisa em Medievalística. O presente trabalho foi realizado com apoio da Coordenação de Aperfeiçoamento de Pessoal de Nível Superior - Brasil (CAPES) - Código de Financiamento 001. E-mail: luciano.vianna@upe.br

(iD http://orcid.org/0000-0001-7355-7609

Recebido em: 09 de abril de 2020 